\title{
Facilitating Mental Health Service Use for Caregivers: Referral Strategies among Child Welfare Caseworkers
}

\author{
Alicia C. Bunger, Ph.D., MSW, \\ Cecil G. Sheps Center for Health Services Research, University of North Carolina - Chapel Hill, \\ 725 Martin Luther King Jr. Blvd; CB \#7590, Chapel Hill, NC 27599-7590, bunger@schsr.unc.edu, \\ Phone: 919-843-6103, Fax: 919-966-1634
}

Emmeline Chuang, Ph.D., and

Graduate School of Public Health, San Diego State University, echuang@mail.sdsu.edu

Bowen McBeath, Ph.D., MSW

School of Social Work and Hatfield School of Government, Portland State University, mcbeath@pdx.edu

\begin{abstract}
Unmet needs for mental health care are common among caregivers involved in the child welfare system. Although child welfare caseworkers are well positioned to identify service needs and refer caregivers to treatment, little is known about the types of referral strategies used in practice, or their effectiveness for promoting mental health service use. The current study examined child welfare caseworkers' use of different referral strategies and the extent to which these strategies are associated with caregivers' receipt of mental health services within a national sample of child welfare cases. Analyses of the second cohort of families from the National Survey of Child and Adolescent Well-Being suggest that child welfare workers more often use informational strategies for referring caregivers, including suggesting treatment or providing information about treatment options. However, social referral strategies such as providing caregivers with direct assistance in completing applications and making and attending appointments were associated with a greater likelihood of caregivers receiving mental health services. Findings support evidence from other service contexts that service use is facilitated by caseworkers' direct support for arranging services. Implications for research and for child welfare managers and administrators are discussed.
\end{abstract}

\section{Introduction}

Caregivers involved with the child welfare system due to suspected or verified child maltreatment are disproportionately likely to have strong and persistent mental health needs. Recent studies suggest that over half of child welfare-involved caregivers meet diagnostic criteria for major mood disorders such as depression (Burns et al., 2010; Marcenko, Lyons, \& Courtney, 2011). Mental illness can negatively impact parenting skills (Oyserman, Mowbray, Meares, \& Firminger, 2000) and child developmental outcomes (Cicchetti, Rogosch, \& Toth, 1998) and may also increase risk of child maltreatment (Rinehart et al.,

(C) 2011 Elsevier Ltd. All rights reserved.

Correspondence to: Alicia C. Bunger.

Publisher's Disclaimer: This is a PDF file of an unedited manuscript that has been accepted for publication. As a service to our customers we are providing this early version of the manuscript. The manuscript will undergo copyediting, typesetting, and review of the resulting proof before it is published in its final citable form. Please note that during the production process errors may be discovered which could affect the content, and all legal disclaimers that apply to the journal pertain. 
2005). As a result, caregivers with mental health needs are more likely to be involved in the child welfare system than other caregivers (Park, Solomon, \& Mandell, 2006). Once involved in the child welfare system, mental health disorders can also negatively influence caregivers' engagement in case planning, decision making, and other child welfare services (Sheppard, 2002).

To reduce the occurrence of these undesirable effects and increase opportunities for positive outcomes for youth and families, child welfare agencies have historically sought to link caregivers with culturally and clinically appropriate mental health services. Research suggests that connecting caregivers to community-based mental health care can increase the likelihood of family reunification (Marsh, Ryan, Choi, \& Testa, 2006). However, despite the potential benefits of mental health treatment, only a small proportion of caregivers who become involved with the child welfare system receive needed mental health services. For example, Burns and colleagues (2010) tracked 2,959 maternal caregivers with depression whose children remained in the home for three years after families' initial involvement with the child welfare system and found that only a third of caregivers had received mental health services. Similarly, in examining 3,340 caregivers who were involved with the child welfare system for at least 18 months, Libby et al. (2006) found that only $23 \%$ of caregivers with behavioral health needs received services.

While these studies identify the child- and family-level correlates of caregivers' mental health service utilization, the extant child welfare literature has not yet examined the contribution of child welfare caseworkers in linking caregivers with needed behavioral health services. This knowledge gap can be organized into two related research topics. First, the specific strategies that caseworkers use to connect caregivers with needed mental health care are unclear. Second, no empirical study has sought to model the relationship between the use of these strategies and caregivers' receipt of needed mental health services (or lack thereof). These two unexplored research topics have important implications for frontline practice and policymaking in child welfare, as they concern the principal mechanisms through which the child welfare system can equitably and efficiently respond to caregivers' mental health needs in promoting the safety and well-being of families.

Application of Andersen's behavioral model, a theoretical framework commonly used in health and mental health services research (Andersen, 1995), highlights the potentially prominent role of child welfare caseworkers in facilitating caregivers' mental health service utilization. According to Andersen's model, low rates of mental health service use among caregivers involved with the child welfare system can be attributed to both individual and contextual (i.e., organizational and societal) factors (Andersen, 2008). At the individual level, predisposing, enabling, and need-related factors are key determinants of mental health service use (Andersen, 1995). Client-level predisposing factors include demographic characteristics such as age, sex, race/ethnicity, and individual beliefs about mental health care. For example, previous research suggests that caregivers belonging to racial/ethnic minority groups and those who are skeptical about mental illness and/or treatment are less likely to utilize mental health services than other individuals (Altman, 2003; Cairney \& Wade, 2002; Rosen, Tolman, \& Warner, 2004; Staudt, 2006). Client-level enabling factors refer to the family and community resources available to help individuals obtain care, which can also significantly impact mental health service utilization. For example, caregivers who lack health insurance or a regular mode of transportation may be less likely to obtain mental health treatment (Rosen et al., 2004). Finally, client need-related factors include both perceived and evaluated mental health needs, which can influence caregivers' help-seeking behaviors. 
Within the broader societal and organizational context in which mental health services are delivered, frontline provider behaviors have also been identified as playing a critical role in caregivers' mental health service use (Stiffman et al., 2001; Stiffman, Pescosolido, \& Cabassa, 2004). For example, previous empirical research has shown that non-mental health providers such as child welfare caseworkers can help facilitate caregivers' access to needed services (Wells, Golding, Hough, Burnam, \& Karno, 1998). These caseworkers often work closely with families during the case plan development process and are uniquely positioned to identify caregivers' unmet needs and connect them to appropriate health and mental health services (Cash \& Berry, 2002). As families' initial point of contact with the broader service system, these frontline providers may serve as important gateways to mental health and other social services (Bunger, Stiffman, Foster, \& Shi, 2009; Kohl, Barth, Hazen, \& Landsverk, 2005).

However, as noted previously, little is known about the specific referral strategies caseworkers use to connect families to non-child welfare services or the relative influence of these practices on caregivers' actual service receipt. To address this gap in the literature, the current study utilizes data from a nationally representative sample of families investigated for child maltreatment to achieve two overarching study objectives. First, we explore the extent to which caseworkers engage in different types of referral practices. Second, we examine whether these practices are associated with caregiver mental health service receipt, controlling for predisposing, enabling, and need-based caregiver characteristics. To inform our empirical examination of child welfare referral actions, we first review the literature concerning referral strategies used by caseworkers to promote service use in child welfare and other related service sectors.

\subsection{Referral Strategies for Connecting Caregivers to Services}

Caseworker referrals, which involve transferring the care of clients from one provider to another with more appropriate specialized expertise (Shortell \& Anderson, 1971), often serve as a first step in caregivers' path to service. However, the specific actions and steps that caseworkers take during the referral process can vary substantially by caseworker. Some caseworkers merely suggest that caregivers receive services while others provide more directive forms of assistance such as helping caregivers schedule and attend appointments.

In the current study, we categorize different types of caseworker referral strategies as being either "informational" or "social". Caseworkers' use of these informational and social referral strategies are not perceived as mutually exclusive; caseworkers may engage in one, both, or neither of these referral strategies as part of their work with families. Informational referral strategies seek to increase clients' knowledge (of mental health disorders, services and providers) and motivation to seek care by providing information to the client (Fisher \& Fisher, 2000; Noguchi, Albarracin, Durantini, \& Glasman, 2007). Examples of informational strategies include recommending that clients receive services or providing information about service providers in the community. When informational strategies are used, clients may be alerted to potential mental health resources and referred to a provider, yet the responsibility for seeking out providers and utilizing services primarily rests primarily upon clients.

In contrast, social referral strategies seek to reduce barriers to service utilization by having caseworkers directly arrange for services on clients' behalf (Albarracin et al., 2005). Examples of social referral strategies include providing caregivers with direct assistance in scheduling treatment appointments, completing paperwork or assembling application documents on behalf of clients, and/or accompanying clients to and from appointments (Hesse, 1976). Social referral strategies can help caregivers overcome barriers deriving from 
inadequate resources and/or other logistical concerns by directly integrating them into service providers' social networks (Stiffman et al., 2004).

While no known study focused on child welfare populations has examined the prevalence and influence of informational and social referral strategies on service use, research in other human service sectors suggest that social referral strategies may be particularly effective at facilitating service use in hard-to-reach populations, such as low-income families and individuals for whom English is a second language. For example, Mathieson \& Kronenfeld (2010) found that helping clients in low-income families complete health insurance applications improved their service engagement. Cuffel (2002) found that for clients transitioning from inpatient to outpatient psychiatric care, making an appointment and placing a follow up call improved clients' service use. Other research suggests that a combination of informational and social referral strategies may be most effective at changing clients' care-seeking behaviors. Hesse (1976) found that a combination of referral strategies (e.g., assisting with paperwork and applications, and providing transportation and accompaniment to appointments) increased mental health service utilization among Spanishspeaking clients in urban neighborhoods. Albarracin et al. (2005) found that providing clients with both educational information and active logistical assistance with care-seeking behaviors was more effective at reaching a diverse population than just adopting a single approach. These studies provide further support for the potential impact of frontline providers on families' care-seeking behaviors and suggest the importance of examining the comparative influence of informational and social referral strategies on service utilization of child welfare-involved families.

\subsection{Study Focus and Hypothesis}

The current study examined child welfare caseworkers' use of different referral strategies (i.e., informational, social, a combination of the two, or neither) and the extent to which these strategies are associated with caregivers' receipt of needed mental health services. Previous research has shown that caregivers involved with the child welfare system are more likely to be economically distressed, unemployed, and experience multidimensional service needs (U.S. DHHS, 2001) but are less likely to receive benefits than other caregivers (Marcenko, Lyons, \& Courtney, 2011; Hook, Lee, Marcenko, \& Romich, 2011). In particular, caregivers affected by behavioral health disorders such as mental illness are likely to experience personal barriers to self-sufficiency that make it difficult for them to seek benefits and services on their own (Jayakody, 2000; Taylor \& Barusch, 2004). For these caregivers, we hypothesize that caseworkers' use of either social referral strategies or a combination of social and informational strategies will increase caregivers' odds of mental health service receipt more than either just an informational referral strategy or no referral at all.

\section{Methods}

\subsection{Data and Sample}

The current study utilized quantitative data from the second cohort of families from the National Survey of Child and Adolescent Well-Being (NSCAW). NSCAW is the only national, longitudinal study of families who were subjects of child abuse or neglect investigations or assessments conducted by U.S. Child Protective Services (CPS) agencies. NSCAW was funded by the Administration for Children and Families within the U.S. Department of Health and Human Services, with field data collection carried out by Research Triangle Institute (RTI) International (Dowd et al., 2010). A complex sampling design involving two stages of stratification was utilized. States requiring CPS agency first contact of participants were excluded from the sampling frame. With the second cohort of 
families (NSCAW II), the first level of sample stratification consisted of 81 primary sampling units (PSUs) located within 30 states. Within these PSUs, children were sampled from all child welfare investigations or assessments that were completed between February 2008 and April 2009. Detailed retrospective assessments of family context and well-being were collected through interviews with children, current caregivers, and investigative caseworkers. This study draws on the baseline interviews (wave one data) that were conducted between March 2008 and September 2009, and occurred on average approximately 4 months after the completion of the child welfare investigation/assessment. Investigative caseworkers were also asked to provide information on their background and demographics, the services provided to families, and the specific referral methods that caseworkers used to facilitate family members' service use.

The initial NSCAW II sample consisted of 5,873 families. Investigative caseworker interviews were completed for only 5,091 of the 5,873 cases. Given the current study's focus on the association between caseworker referral activities and caregiver mental health service receipt, we further restricted the operational study sample to include only caregivers who were assessed by caseworkers as needing mental health services and for whom a mental health service referral was made (i.e. who were not already receiving services). Application of these restrictions reduced the sample to 802 caregivers within 82 public child welfare agencies. Listwise deletion for item missingness resulted in a final analytic sample of 640 caregivers within 78 agencies.

The sampling weights within NSCAW account for differential selection probabilities as well as potential bias resulting from survey non-response and thus yield estimates that are nationally representative of all families subject to child maltreatment investigations or assessments conducted by CPS and living in states not requiring CPS agency first contact of sample members (Dowd et al., 2010; Pfeffermann, Skinner , Holmes, Goldstein, \& Rasbash, 1998). However, these weights do not account for item non-response. Weighted t-tests conducted to determine if data were missing at random indicated that caregivers in the final analytic sample did not differ significantly from those excluded due to listwise deletion in other model variables. Therefore, we concluded that sampling error due to item-level missingness was statistically ignorable within our sample.

\subsection{Measures}

2.2.1. Dependent Variable: Mental Health Service Receipt-A dichotomous dependent variable representing caregiver mental health service receipt was used in multivariate logistic regression analyses. This variable was set equal to 1 if caseworkers indicated that caregivers had received any mental health services as the result of caseworker referral.

2.2.2. Caseworker Referral Activities-Caseworker referral activities were also based on caseworker self-report and were operationalized as four mutually-exclusive, dichotomous variables: (1) caseworker referred but did not report a specific type of referral activity; (2) caseworker provided only informational referral activities (referent group); (3) caseworker provided only social referral activities; and (4) caseworker provided both informational and social referral activities. Informational referral activities included suggesting that caregivers receive services, providing caregivers with names and numbers of service providers, and/or following up with caregivers to determine whether services were provided. Social referral activities included directly assisting caregivers with completing or filing service applications, making an appointment for the caregiver, and/or accompanying caregivers to appointments. 
2.2.3. Control Variables-Two county-level, contextual variables were included to account for potential confounders of the association between focal predictors and caregivers' odds of mental health service receipt. A dichotomous measure indicating whether the child welfare agency was located in an urban area served as a control for rural-urban differences in service provision and as a proxy for organization size (Alexander, Nank, \& Stivers, 1999; Johnston \& Romzek, 1999). A second measure controlling for the percentage of the total county population living below the federal poverty level served as a proxy for overall community needs, which has also been shown to be associated with mental health service need (Leventhal \& Brooks-Gunn, 2003).

In addition, certain individual factors known to influence families' interactions with child welfare caseworkers and/or influence the odds of mental health service receipt were included as control variables. These factors were caregiver age; caregiver race/ethnicity (Amaro et al., 2005; Chow, Jaffee, \& Snowden, 2003); whether the caregiver had cooccurring mental health and substance abuse problems (Watkins, Audrey Burnam, FuanYue Kung, \& Paddock, 2001); the most serious type of maltreatment experienced by the child (Barnett, Manly, \& Cicchetti, 1993); a 3-point global measure of cumulative family risk, with values ranging from " 1 " = "low family risk" to " 3 " = "high family risk", that was based upon investigative caseworkers' assessment of the presence of 21 risks, e.g., previous child welfare service use history, child special needs, high family stress, or history of domestic violence (Barth et al., 2008; McCrae \& Barth, 2008; Mersky et al., 2009); child age; whether the child was placed out-of-home; and whether the family had received any child welfare services after the close of the investigation/assessment.

\subsection{Analyses}

Multivariate logistic regressions were employed to examine the comparative influence of each type of caseworker referral strategy on caregivers' odds of receiving mental health services, controlling for the aforementioned individual- and county-level covariates. NSCAW data have a hierarchical structure, with families and their caseworkers nested within child welfare agencies. In initial analyses, a fully unconditional random effects model indicated significant variation across child welfare agencies in caregivers' likelihood of mental health service receipt, with an intraclass correlation coefficient of $6.7 \%$. Statistical power considerations, however, prevented the use of multilevel analyses that specifically modeled inter-organizational differences in caregivers' odds of service utilization. Because the final analytic sample contained only a relatively modest number of level-2 units (78 child welfare agencies) with an average group membership of 8 caregivers per agency, all models were therefore analyzed as single-level equations incorporating a post-hoc adjustment to standard errors that accommodated clustering of caregivers within child welfare agencies (de Leeuw \& Meijer, 2008).1

Analyses were conducted using the Stata 11.0 -svy- module (StataCorp, 2009). The -svymodule permits analyses that account for the complex survey design of the data, accommodating probability weights and stratification as well as correlations in outcomes across caregivers located within the same child welfare agencies. The post-hoc adjustment to standard errors used in the -svy- module is similar to that used by the robust standard error

\footnotetext{
${ }^{1}$ In multilevel models, the number of level-2 units has a greater effect on parameter and variance estimates than the number of individuals per group (Hox, 2002). With unbalanced data such as NSCAW, estimations of coefficients and standard errors in multilevel models rely on large-sample theory. When the number of level-2 units is small $(\leq 50)$, multilevel models with continuous dependent variables produce unbiased regression coefficients but underestimate standard errors and variance components (Maas \& Hox, 2004). In multilevel models with binary dependent variables such as that within the current study, small to modest samples of level-2 units result in biased estimates premised on inaccurate assumptions about variable distributions (Raudenbush \& Bryk, 2002). With multilevel logistic models, parameter and variance estimates are completely unbiased only with 100 level-2 units with group membership of 50 or higher (Moineddin, Matheson, \& Glazier, 2007).
} 
procedure, differing only by a constant multiplier (StataCorp, 2009). Reflecting the dichotomous nature of the dependent variable, the logistic link function was used. Phi correlations between independent variables as well as variance inflation factors (VIF) did not indicate any problematic collinearity. Specifically, correlations were all less than 0.4 with VIF values of less than 2.5, which is the threshold above which multicollinearity may be a concern in logistic regression (Allison, 1999). This secondary data analysis was approved by the Institutional Review Board at the second author's home institution. The original data collection was approved by an Institutional Review Board at RTI International.

\section{Results}

\subsection{Sample Characteristics}

Table 1 lists weighted descriptive statistics for all study measures. The sample consists of 640 caregivers who were referred to mental health services. Caregivers tended to be female (79\%), and most were under age $35(54 \%)$. A slight majority (56\%) of the caregivers were Caucasian, followed by Hispanic (20\%), non-Hispanic Black (11\%), and other minorities, such as American Indian or Asian/Pacific Islanders (13\%). Notably, 34\% of caregivers had a co-occurring substance use issues. The most serious type of maltreatment present in the caregivers' household was usually neglect (36\%), followed by physical abuse (16\%), substance abuse (13\%), sexual abuse (7\%), domestic violence (6\%), or some other maltreatment type (22\%). Their children ranged in age from just born to 17 years, although the average was about six years. Roughly a quarter of caregivers $(24 \%)$ had children placed outside of the home and $45 \%$ were receiving child welfare services after the investigation was closed. Families in our sample tended to reside in urban areas (68\%) and in counties with an average poverty rate of about $14 \%$.

\subsection{Caregivers' Mental Health Service Receipt and Prevalence of Different Referral Activities}

Of the 640 caregivers in the final analytic sample who were referred to mental health care, approximately $77 \%$ received some mental health services. The types of mental health services received by caregivers included overnight/inpatient services (7\%), outpatient care $(62 \%)$, day treatment or partial hospitalization (5\%), or some other type of mental health treatment $(27 \%)$.

The first objective of this study was to describe the prevalence of different types of referral strategies. As can be seen at the bottom of Table 1, the most common type of caseworker referral activity involved providing only informational referrals, with $58 \%$ of caseworkers having used only this referral strategy with sample caregivers. Only $7 \%$ of caseworkers reported engaging in no specified type of referral activities on behalf of caregivers, $8 \%$ reported engaging in only social referral activities, and $27 \%$ of caseworkers reported using a combination of informational and social referral activities to facilitate caregivers' service use.

Table 2 describes in detail the prevalence of specific types of informational and social referral activities. Providing caregivers with names and phone numbers for specific providers was the most commonly used informational strategy (59\%). Over half of the caregivers received general recommendations for mental health care (55\%). Caseworkers engaged in follow-up work for $47 \%$ of the caregivers referred for mental health treatment.

As noted above, caseworkers reported engaging in social referral activities less frequently than informational referral activities. Among caregivers referred for mental health services, $24 \%$ had appointments arranged by their caseworker and $19 \%$ of caregivers received 
assistance in completing applications. Only $7 \%$ of caregivers were accompanied to their appointments by their caseworker.

\subsection{Relationship between Referral Strategies and Use of Mental Health Services}

The second study objective was to use multivariate logistic regression analysis to examine the extent to which different types of referral strategies were associated with caregivers' odds of having received any mental health services. As can be seen in Table 3 and as hypothesized, caregivers whose caseworkers engaged in social referral activities had significantly higher odds of receiving mental health services than caregivers whose caseworkers engaged in informational referral activities only (OR 5.73, $\mathrm{p}<0.05$ for social referral activities only; OR $13.31, \mathrm{p}<0.01$ when caseworkers engaged in both informational and social referral strategies). There were no significant differences in the odds of service receipt between caregivers whose caseworkers engaged in informational referral activities only and caregivers whose caseworkers did not engage in any specified type of referral activities.

Several control variables were also significantly associated with the odds of caregivers receiving mental health services. Sexual abuse significantly increased caregivers' odds of mental health service use (OR 18.59, $\mathrm{p}<0.01$ ). Compared to white caregivers, Hispanic caregivers and caregivers who were non-Black, non-Hispanic minorities had greater odds of receiving mental health services (OR 16.41, $\mathrm{p}<0.01$ for Hispanic; OR 10.68, $\mathrm{p}<0.01$ for other minorities). Caregivers in households where substance abuse was the most serious type of maltreatment had significantly lower odds of receiving mental health services (OR 0.33 , $\mathrm{p}<0.05)$ whereas those in families receiving child welfare services after the close of the investigation/assessment had higher odds of receiving mental health services (OR 2.71, $\mathrm{p}<0.01$ ). Finally, being located in a county with a higher percentage of individuals living below the federal poverty level decreased caregivers' odds of receiving needed mental health services (OR 0.90, $\mathrm{p}<0.05)$.

\section{Discussion}

This paper examined the informational and social strategies that front-line caseworkers used to facilitate the provision of mental health services to child welfare-involved caregivers. Caregiver participation in mental health services has been shown to be related to reduced child maltreatment risk and improved permanency outcomes (Baydar, Reid, \& WebsterStratton, 2003; DePanfilis \& Zuravin, 2002; Gregoire \& Schultz, 2001; Littell, 2001; Marsh et al., 2006). For caregivers whose service plans include mental health treatment goals, accessing services is often a prerequisite for timely parent-child reunification. Linking caregivers with mental health services may therefore serve as an important point of intervention for child welfare agencies and caseworkers seeking to improve child and family safety, permanency, and well-being.

Drawing upon analyses of a nationally representative sample of caregivers from the second cohort of NSCAW families, this study determined that child welfare caseworkers used informational strategies to refer caregivers to mental health services twice as frequently as they adopted social referral strategies. As compared with informational strategies alone, caregivers whose caseworkers utilized social referral strategies (either by themselves or in combination with informational strategies) had significantly increased odds of mental health service receipt. That is, caregivers whose caseworkers assisted them in completing paperwork requesting mental health services, who helped them make appointments, or who accompanied them to treatment sessions were more likely than other caregivers to have received needed mental health care. 


\subsection{Study Limitations}

These results should be understood relative to a number of study limitations. First, these data represent caseworkers' reports on their referral actions and may be subject to social desirability or recall biases. Second, in order to understand the nature of referral strategies, the sample was restricted to families where there was an identified caregiver mental health service need and a referral for services, therefore the study does not reflect the full continuum of unmet mental health service needs. In particular, caregivers with mental health service needs that were undetected by the caseworker, or those who did not receive a referral were not included in the analysis. This particular selection approach may account for why the rate of caregiver mental health service use in this study (77\%) is so much higher than in previously published reports, which are based on less-restricted samples [e.g. with only a caseworker-identified service need as in Libby et al (2006), or clinical assessments of mental health problems based on caregiver reports as in Burns et al (2010)]. Third, because these NSCAW data were gathered via a cross-sectional survey design, it was not possible to test for a causal relationship between different caseworker referral strategies and caregiver mental health service usage. Internal validity was also limited by a number of omitted explanatory variables which, had they been present in statistical models, might have resulted in different parameter estimates for referral strategies.

Fourth, measures pertaining to the specific manner in which caseworkers carried out each referral strategy were unavailable. It was also not possible to determine the appropriateness, quality, or duration of mental health services received. NSCAW study measures only evaluate whether any services were received; data are not available on whether these services were evidence-based, or clinically or culturally appropriate. If available, more granular measurement of caseworker activities and caregiver mental health services may have reduced overall levels of measurement error and improved measurement validity. Finally, while based on a national sample, study findings are only generalizable to families subject to child maltreatment investigations or assessments conducted over 2008-2009 and living in states not requiring CPS agency first contact of sample members. Findings may not be applicable to caregivers whose children are currently receiving ongoing foster care case management services.

\subsection{Implications for Research, Practice, and Policy}

With these limitations in mind, current study results suggest a number of implications for research, practice, and policy. First, future research should examine in greater depth the association between social referral strategies and caregiver receipt of mental health care and whether these findings are applicable to specific mental health conditions and specific subpopulations of caregivers within child welfare. Hispanic, and other non-Black, nonHispanic minority caregivers in this study were more likely to receive mental health services than white caregivers. Caregivers from these historically oppressed racial and ethnic groups are disproportionately represented in child welfare client populations but often experience greater challenges with locating and receiving services from culturally-syntonic mental health providers than Caucasian caregivers (Briggs \& McBeath, 2010). Research focused on determining whether social referral strategies are associated with caregivers' timely access to culturally appropriate mental health care, controlling for client characteristics as well as those pertaining to the local service provider community (Freisthler, 2004; Freisthler, Merritt, \& LaScala, 2006) could help identify factors related to reductions in racial/ethnic disparities in mental health service use.

Further research is also needed to examine why social referral strategies and/or a combination of social and informational referral strategies have a more positive impact caregiver service receipt than informational strategies alone. Research suggests that mental 
health referrals made by some providers are more successful than others and that trust between clients and providers may play a critical role in this process (Olfson, 1991; Laugharne et al., 2011); however, the specific mechanisms by which providers impact clients' utilization of care is unknown. Social strategies may facilitate caregivers' mental health service use by enhancing caregivers' comfort, motivation, and/or skills needed to seek out mental health services. Another possible explanation relates to the process of caseworker-caregiver engagement. Unlike entry into other public service systems, involvement with child welfare is often involuntary (Fluke \& Oppenheim, 2010). Assisting caregivers with applying for, scheduling, and attending appointments may require caseworkers to build positive alliances with family members in involuntary and voluntary service settings than informational referral strategies. In these situations, it is possible that caregivers' increased engagement in treatment is the byproduct of increased trust and improved relationships with caseworkers, rather than of increased education or skill development. By this logic, the amount of time caseworkers devote to developing a social connection with caregivers could also serve as a direct proxy for parent engagement in service planning (Kemp, Marcenko, Hoagwood, \& Vesneski, 2009).

Disentangling these effects and illuminating the mechanisms by which social referral strategies increase caregiver treatment utilization would be of great utility to both research and practice. Qualitative research could explore caseworkers' rationale for using informational versus social referral strategies as well as caregivers' perspectives on how caseworker actions impact their decision to use or not use services. Quantitative studies could examine associations between caseworkers' use of informational and/or social referral strategies and levels of client engagement, as perceived by caregivers versus caseworkers, specifically with regards to caregivers' attitudes toward and willingness to pursue mental health treatment. These studies might also explore the potentially moderating effects of caseworker and caregiver racial/ethnic similarity as well as client voluntary/involuntary treatment status.

The current study also has a number of implications for child welfare practice and policymaking. Foremost among these is the need to identify front-line casework practices that improve client outcomes. Little information exists concerning the front-line and organizational practices that best promote desired child and family outcomes. The manner in which caseworkers interact with children and families, link clients to community-based services, prepare for court and other agency meetings, and complete necessary paperwork has been little studied (for notable exceptions, see Smith, 2009; Smith \& Donovan, 2003; Smith \& Manfredo, 2011). However, findings from the current study imply that supervisors and administrators should identify caseworker practices within their agencies that appear to be associated with enhanced client service use and safety, permanency, and well-being outcomes. Such knowledge may directly inform agency strategies to promote effective caseworker practices.

Policymakers and child welfare systems invested in linking clients to needed mental health services may consider providing training and support for caseworkers to address caregivers' attitudes towards mandated mental health treatment and enhance caseworker engagement with families (Staudt, 2006). So that caseworkers can knowledgeably help caregivers use services, administrators may wish to develop training curricula that familiarize caseworkers with local mental health providers, the nature of available services, and application procedures. Effort may also need to be expended on collaborating with court officials and local service providers around permanency planning, so that caseworkers and caregivers may access court-ordered services expeditiously. Finally, policymakers and agencies should examine whether front-line caseworkers are provided sufficient resources to engage caregivers in service planning. Developing and implementing social referral strategies- 
including assisting caregivers with paperwork and accompanying them to appointmentsrequire substantial time and commitment on the part of caseworkers. If caseworkers are faced with high caseloads, competing time demands, and insufficient resources and support, they may have little discretion and/or time to work closely with caregivers. Therefore, policymakers and administrators seeking to improve outcomes for child welfare-involved families may need to provide sufficient resources for caseworkers to engage with families and link them effectively with needed services.

\section{Conclusion}

Child welfare caseworkers serve a key role in helping caregivers access needed mental health services. Study findings suggest that social referral strategies in which caseworkers directly assist caregivers with applying for, scheduling, and/or attending appointments are positively associated with caregivers' odds of utilizing mental health services. Encouraging caseworkers to play a more active role in facilitating service connections for families and researchers to further examine the impact of caseworker behaviors on families' engagement in treatment may help child welfare systems enhance safety, permanency and well-being for children and their families.

\section{Highlights}

- This study examined different types of caseworker referral strategies.

- Caseworkers most often use informational referral strategies.

- However, arranging services may be more effective.

- These social strategies were linked with caregiver mental health service use.

\section{Acknowledgments}

Data from the National Survey on Child and Adolescent Well-Being were provided by the National Data Archive on Child Abuse and Neglect and developed under contract with the Administration on Children, Youth, and Families, U.S. Department of Health and Human Services (ACYF/DHHS). The information and opinions expressed herein reflect solely the position of the authors. This research was supported by the National Research Service Award Postdoctoral Traineeship from the National Institute of Mental Health sponsored by the Cecil G. Sheps Center for Health Services Research, University of North Carolina at Chapel Hill, and the Department of Psychiatry and Behavioral Sciences, Duke University Medical Center, Grant No: T32 MH019117.

\section{References}

Albarracin D, Gillette JC, Earl AN, Glasman LR, Durantini MR, Ho M-H. A test of major assumptions about behavior change: A comprehensive look at the effects of passive and active HIV-prevention interventions since the beginning of the epidemic. Psychological Bulletin. 2005; 131(6):856-897. [PubMed: 16351327]

Alexander J, Nank R, Stivers C. Implications of welfare reform: Do nonprofit survival strategies threaten civil society? Nonprofit and Voluntary Sector Quarterly. 1999; 28(4):452-475.

Allison, PD. Logistic Regression Using SAS: Theory and Application. Cary, NC: SAS Institute Inc.; 1999.

Altman JC. A qualitative examination of client participation in agency-initiated services. Families in Society: The Journal of Contemporary Human Services. 2003; 84(4):471-479.

Amaro H, Larson MJ, Gampel J, Richardson E, Savage A, Wagler D. Racial/ethnic differences in social vulnerability among women with co-occurring mental health and substance abuse disorders: Implications for treatment services. Journal of Community Psychology. 2005; 33(4):495-511.

Andersen RM. Revisiting the behavioral model and access to medical care: Does it matter? Journal of Health and Social Behavior. 1995; 36(1):1-10. [PubMed: 7738325] 
Andersen RM. National health surveys and the behavioral model of health services use. Medical Care. 2008; 46(7):647-653. [PubMed: 18580382]

Baydar N, Reid MJ, Webster-Stratton C. The role of mental health factors and program engagement in the effectiveness of a preventive parenting program for Head Start mothers. Child Development. 2003; 74(5):1433-1453. [PubMed: 14552407]

Barnett, D.; Manly, J.; Cicchetti, D. Defining Child Maltreatment: The interface between policy and research. In: Cicchetti, D.; Toth, SL., editors. Advances in Applied Developmental Psychology: Child Abuse, Child Development and Social Policy. Vol. Chapter 2. Norwood, NJ: Ablex Publishing Corp; 1993. p. 7-73.

Barth R, Weigensberg E, Fisher P, Fetrow B, Green R. Re-entry of elementary aged children following reunification from foster care. Children and Youth Services Review. 2008; 30(4):353-364. [PubMed: 21765570]

Briggs HE, McBeath B. Infusing culture into practice: Developing and implementing evidence-based mental health services for African American foster youth. Child Welfare. 2010; 89(1):31-60. [PubMed: 20565012]

Bunger AC, Stiffman AR, Foster KA, Shi P. Child welfare workers connectivity to resources and youth's receipt of services. Advances in Social Work. 2009; 10(1):1-21.

Burns, BJ.; Mustillo, SA.; Farmer, EMZ.; Kolko, DJ.; McCrae, J.; Libby, AM.; Bruce Webb, M. Caregiver Depression, Mental Health Service Use, Child Outcomes. In: Webb, MB.; Dowd, Kathryn; Harden, BJ.; Landsverk, John; Testa, Mark, editors. Child Welfare, Child Well-Being, New Perspectives From the National Survey of Child and Adolescent Well-Being. 2010. p. 351-379.

Cairney J, Wade TJ. Single parent mothers and mental health care service use. Social Psychiatry and Psychiatric Epidemiology. 2002; 37(5):236-242. [PubMed: 12107716]

Cash SJ, Berry M. Family characteristics and child welfare services: Does the assessment drive service provision? Families in Society: The Journal of Contemporary Human Services. 2002; 83(5/6):499507.

Chow JC-C, Jaffee K, Snowden L. Racial/ethnic disparities in the use of mental health services in poverty areas. American Journal of Public Health. 2003; 93(5):792-797. [PubMed: 12721146]

Cicchetti D, Rogosch FA, Toth SL. Maternal depressive disorder and contextual risk: contributions to the development of attachment insecurity and behavior problems in toddlerhood. Development and Psychopathology. 1998; 10(2):283-300. [PubMed: 9635225]

Cuffel BJ. Predictive models and the effectiveness of strategies for improving outpatient follow-up under managed care. Psychiatric Services. 2002; 53(11):1438-1443. [PubMed: 12407272]

de Leeuw, J.; Meijer, E. Handbook of Multilevel Analysis. de Leeuw, J.; Meijer, E., editors. New York, NY: Springer Science+Business Media, LLC; 2008.

DePanfilis D, Zuravin SJ. The effect of services on the recurrence of child maltreatment. Child Abuse \& Neglect. 2002; 26(2):187-205. [PubMed: 11933989]

Dowd, K.; Dolan, M.; Wallin, J.; Miller, K.; Biemer, P.; Aragon-Logan, E.; Wheeless, S., et al. National Survey of Child and Adolescent Well-Being II: Data File User's Manual Restricted Release. Ithaca, NY: National Data Archive on Abuse and Neglect; 2010.

Fisher, JD.; Fisher, WA. Theoretical approaches to individual-level change in HIV risk behavior. In: Suls, J.; Wallston, KA., editors. Handbook of HIV Prevention. New York: KluwerAcademic/ Plenum Publishers; 2000. p. 3-55.

Fluke J, Oppenheim E. Getting a grip on systems of care and child welfare using opposable thumbs. Evaluation and Program Planning. 2010; 33(1):41-44. [PubMed: 19552956]

Freisthler B. A spatial analysis of social disorganization, alcohol access, and rates of child maltreatment in neighborhoods. Children and Youth Services Review. 2004; 26(9):803-819.

Freisthler B, Merritt D, LaScala E. Understanding the ecology of child maltreatment: A review of the literature and directions for future research. Child Maltreatment. 2006; 11(3):263-280. [PubMed: 16816324]

Gregoire KA, Schultz DJ. Substance-abusing child welfare parents: treatment and child placement outcomes. Child Welfare. 2001; 80(4):433-452. [PubMed: 11480487] 
Hesse KAF. The paraprofessional as a referral link in the mental health delivery system. Community Mental Health Journal. 1976; 12(3):252-258. [PubMed: 991589]

Hook, J.; Lee, J.; Marcenko, M. Economically disconnected families involved with child welfare services in Washington State. Seattle, WA: West Coast Poverty Center; 2011.

Hox, JJ. Multilevel Analysis: Techniques and applications. Mahwah, NJ: Erlbaum; 2002.

Jayakody R. Welfare reform, substance use, mental health. Journal of Health Politics, Policy and Law. 2000; 25(4):623-652.

Johnston JM, Romzek BS. Contracting and accountability in state Medicaid reform: Rhetoric, theories, and reality. Public Administration Review. 1999; 59(5):383-399.

Kemp SP, Marcenko MO, Hoagwood K, Vesneski W. Engaging parents in child welfare services: Bridging family needs and child welfare mandates. Child Welfare. 2009; 88(1):101-126. [PubMed: 19653455]

Kohl P, Barth R, Hazen A, Landsverk J. Child welfare as a gateway to domestic violence services. Children and Youth Services Review. 2005; 27(11):1203-1221.

Laugharne R, Priebe S, McCabe R, Garland N, Clifford D. Trust, choice, and power in mental health care: Experiences of patients with psychosis. International Journal of Social Psychiatry. 2011; $57(6)$

Leventhal T, Brooks-Gunn J. Moving to opportunity: An experimental study of neighborhood effects on mental health. American Journal of Public Health. 2003; 93(9):1576-1582. [PubMed: 12948983]

Libby AM, Orton HD, Barth RP, Bruce Webb M, Burns BJ, Wood P, Spicer P. Alcohol, drug, and mental health specialty treatment services and race/ethnicity: A national study of children and families involved with child welfare. American Journal of Public Health. 2006; 96(4):628-631. [PubMed: 16507729]

Littell JH. Client participation and outcomes of intensive family preservation services. Social Work Research. 2001; 25(2):11.

Maas CJM, Hox JJ. Robustness issues in multilevel regression analysis. Statistica Neerlandica. 2004; 58:127-137.

Marcenko MO, Lyons SJ, Courtney M. Mothers' experiences, resources and needs: The context for reunification. Children and Youth Services Review. 2011; 33(3):431-438.

Marsh J, Ryan J, Choi S, Testa M. Integrated services for families with multiple problems: Obstacles to family reunification. Children and Youth Services Review. 2006; 28(9):1074-1087.

Mathieson KM, Kronenfeld JJ. Barriers to enrollment and successful outreach strategies in CHIP: Reflections on the Arizona experience. Journal of Health Care for the Poor and Underserved. 2010; 14(4):465-477. [PubMed: 14619549]

McCrae J, Barth R. Using cumulative risk to screen for mental health problems in child welfare. Research on Social Work Practice. 2008; 18(2):144-159.

Mersky J, Berger L, Reynolds A, Gromoske A. Risk factors for child and adolescent maltreatment: A longitudinal investigation of a cohort of inner-city youth. Child Maltreatment. 2009; 14(1):73-88. [PubMed: 18596199]

Moineddin R, Matheson F, Glazier R. A simulation study of sample size for multilevel logistic regression models. BMC Medical Research Methodology. 2007; 7:34-46. [PubMed: 17634107]

Noguchi K, Albarracin D, Durantini MR, Glasman LR. Who participates in which health promotion programs? A meta-analysis of motivations underlying enrollment and retention in HIV-prevention interventions. Psychological Bulletin. 2007; 133(6):955-975. [PubMed: 17967090]

Olfson M. Primary care patients who refuse specialized mental health services. Archives of Internal Medicine. 1991; 151(1):129-132. [PubMed: 1985587]

Oyserman D, Mowbray CT, Meares PA, Firminger KB. Parenting among mothers with a serious mental illness. American Journal of Orthopsychiatry. 2000; 70(3):296-315. [PubMed: 10953777]

Park JM, Solomon P, Mandell DS. Involvement in the child welfare system among mothers with serious mental illness. Psychiatric Services. 2006; 57(4):493-497. [PubMed: 16603744] 
Pfeffermann D, Skinner CJ, Holmes DJ, Goldstein H, Rasbash J. Weighting for unequal selection probabilities in multilevel models. Journal of the Royal Statistical Society: Series B (Statistical Methodology. 1998; 60(1):23-40.

Raudenbush, SW.; Bryk, AS. Hierarchical Linear Models. Newbury Park, CA: Sage Publications; 2002.

Rinehart DJ, Becker M, Buckley PR, Dailey K, Reichardt CS, Graeber C, VanDeMark NR, et al. The relationship between mothers' child abuse potential and current mental health symptoms. The Journal of Behavioral Health Services \& Research. 2005; 32(2):155-166.

Rosen D, Tolman RM, Warner LA. Low-income women's use of substance abuse and mental health services. Journal of Health Care for the Poor and Underserved. 2004; 15(2):206-219. [PubMed: 15253374]

Sheppard M. Depressed mothers' experience of partnership in child and family care. British Journal of Social Work. 2002; 32(1):93-112.

Shortell SM, Anderson OW. The physician referral process: A theoretical perspective. Health Services Research. 1971; 6(1):39-48. [PubMed: 5569226]

Smith, BD. Service technologies and the conditions of work in child welfare. In: Hasenfeld, Y., editor. Human Services as Complex Organizations. 2nd ed.. Newbury Park, CA: Sage Publications; 2009. p. 253-268.

Smith BD, Donovan EFS. Child welfare practice in organizational and institutional context. Social Service Review. 2003; 77:541-563.

Smith BD, Manfredo IT. Frontline counselors in organizational contexts: A study of treatment practices in community settings. Journal of Substance Abuse Treatment. 2011; 41(2):124-136. [PubMed: 21632198]

StataCorp. Stata Statistical Software: Release 11. College Station, TX: StataCorp LP; 2009.

Staudt M. Treatment engagement with caregivers of at-risk children: Gaps in research and conceptualization. Journal of Child and Family Studies. 2006; 16(2):183-196.

Stiffman, Arlene R.; Striley, C.; Horvath, VE.; Hadley-Ives, E.; Polgar, M.; Elze, D.; Pescarino, R. Organizational context and provider perception as determinants of mental health service use. The Journal of Behavioral Health Services and Research. 2001; 28(2):188-204.

Stiffman, Arlene Rubin; Pescosolido, B.; Cabassa, LJ. Building a model to understand youth service access: The gateway provider model. Mental Health Services Research. 2004; 6(4):189-198. [PubMed: 15588030]

Taylor MJ, Barusch AS. Personal, family, and multiple barriers of long-term welfare recipients. Social Work. 2004; 49(2):175-183. [PubMed: 15124958]

U.S. Department of Health and Human Services. Mental Health: Culture, Race, and Ethnicity - A Supplement to Mental Health: A Report of the Surgeon General. Rockville, MD: U.S. Department of Health and Human Services, Substance Abuse and Mental Health Services Administration, Center for Mental Health Services; 2001.

Watkins KE, Audrey Burnam A, Fuan-Yue Kung F-Y, Paddock S. A national survey of care for persons with co-occurring mental and substance use disorders. Psychiatric Services. 2001; 52(8): 1062-1068. [PubMed: 11474052]

Wells KB, Golding JM, Hough RL, Burnam MA, Karno M. Factors affecting the probability of use of general and medical health and social/community services for Mexican Americans and nonhispanic whites. Medical Care. 1988; 26(5):441-452. [PubMed: 3374179] 
Table 1

Descriptive Statistics for Study Sample (N=640)

\begin{tabular}{|l|c|c|c|c|}
\hline & $\begin{array}{c}\text { Weighted } \\
\text { Mean }\end{array}$ & S.E. & Min & Max \\
\hline Mental Health Service Receipt & & & & \\
\hline Caregiver received mental health services & $77 \%$ & - & 0 & 1 \\
\hline Caseworker Referral Strategies & & & & \\
\hline Informational referral only & $58 \%$ & - & 0 & 1 \\
\hline No specified type of referral activity & $7 \%$ & - & 0 & 1 \\
\hline Social referral only & $8 \%$ & - & 0 & 1 \\
\hline Informational and social referral activities & $27 \%$ & - & 0 & 1 \\
\hline Individual-level control variables & & & & \\
\hline Caregiver age: <35 years & $54 \%$ & - & 0 & 1 \\
\hline Caregiver age: 35-44 years & $19 \%$ & - & 0 & 1 \\
\hline Caregiver age: $45-54$ years & $23 \%$ & - & 0 & 1 \\
\hline Caregiver age: >54 years & $4 \%$ & - & 0 & 1 \\
\hline Caregiver race/ethnicity: White & $56 \%$ & - & 0 & 1 \\
\hline Caregiver race/ethnicity: Non-Hispanic Black & $11 \%$ & - & 0 & 1 \\
\hline Caregiver race/ethnicity: Hispanic & $20 \%$ & - & 0 & 1 \\
\hline Caregiver race/ethnicity: Other minority & $13 \%$ & - & 0 & 1 \\
\hline Co-occurring MH/SA disorder & $34 \%$ & - & 0 & 1 \\
\hline Type of maltreatment: Neglect & $36 \%$ & - & 0 & 1 \\
\hline Type of maltreatment: Physical abuse & $16 \%$ & - & 0 & 1 \\
\hline Type of maltreatment: Sexual abuse & $7 \%$ & - & 0 & 1 \\
\hline Type of maltreatment: Substance abuse & $13 \%$ & - & 0 & 1 \\
\hline Type of maltreatment: Domestic violence & $6 \%$ & - & 0 & 1 \\
\hline Type of maltreatment: Other maltreatment & $22 \%$ & - & 0 & 1 \\
\hline Family risk score & 2.32 & 0.08 & 1 & 3 \\
\hline Child age in years & 5.74 & 0.57 & 0 & 17 \\
\hline Child placement out-of-home & $24 \%$ & - & 0 & 1 \\
\hline Family receiving child welfare services & $45 \%$ & - & 0 & 1 \\
\hline County-level control variables & & & & \\
\hline County: Urban location & & & 0 & 1 \\
\hline County: \% Families below federal poverty & 14.08 & 4.1 & 28.6 \\
\hline
\end{tabular}


Table 2

Prevalence of Specific Referral Strategies Reported by Caseworkers

\begin{tabular}{|c|c|}
\hline & $\underline{\%}$ \\
\hline \multicolumn{2}{|l|}{ Informational Referral Strategies } \\
\hline Suggested caregiver should receive mental health treatment & $55 \%$ \\
\hline Provided caregiver with names and telephone numbers of service providers & $59 \%$ \\
\hline Followed up to see if services were provided & $47 \%$ \\
\hline \multicolumn{2}{|l|}{$\underline{\text { Social Referral Strategies }}$} \\
\hline Assisted caregiver with completing and/or filing service application & $19 \%$ \\
\hline Made an appointment for the caregiver & $24 \%$ \\
\hline Accompanied caregiver to the appointment & $7 \%$ \\
\hline
\end{tabular}




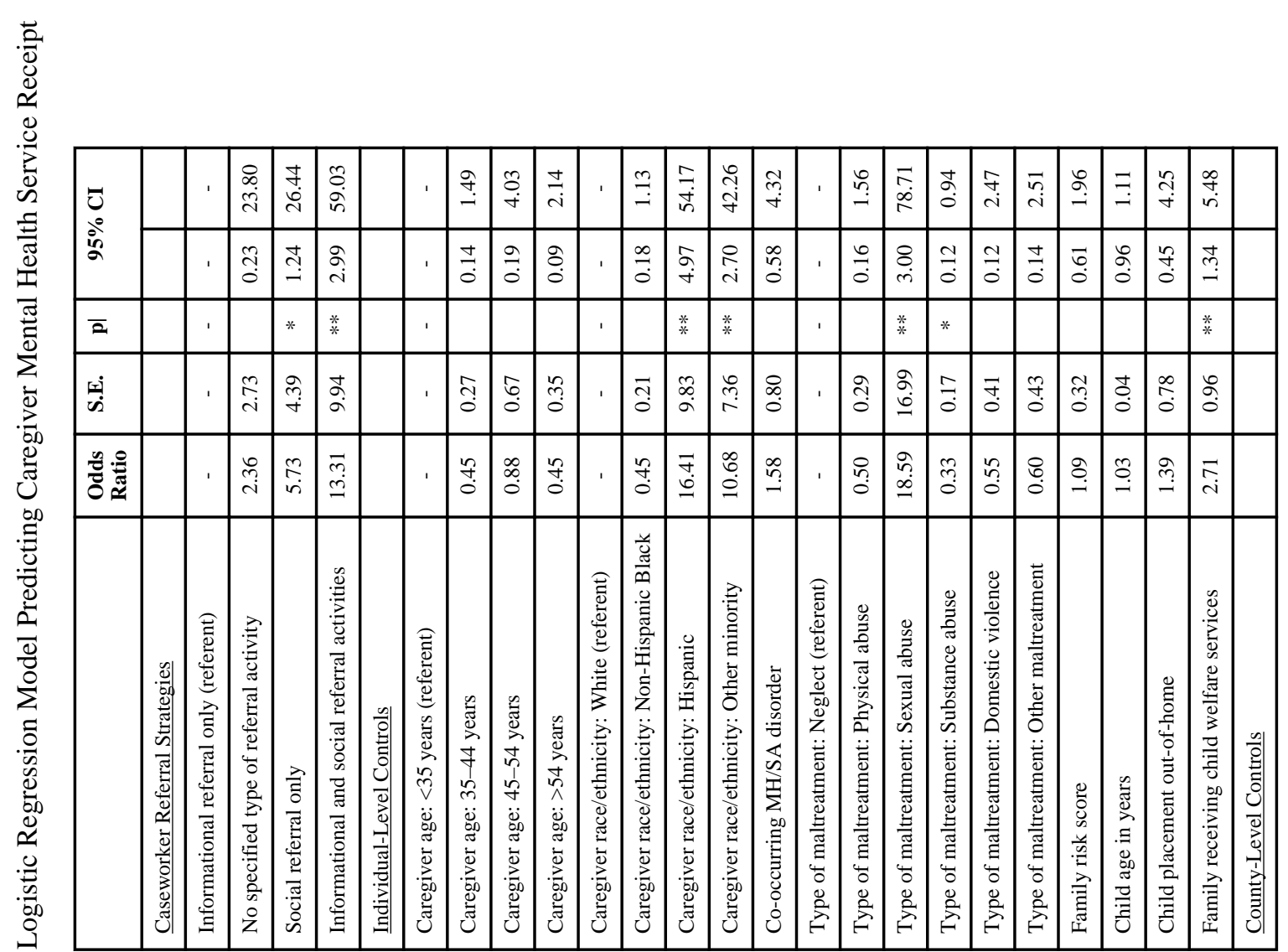




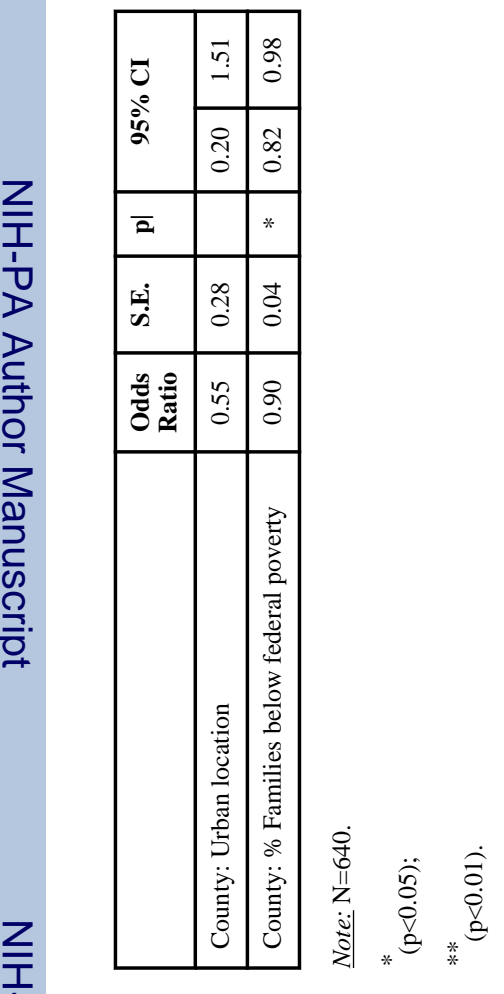

